\title{
Okulöncesi Dönemdeki Çocuklar Uzay Hakkında Neler Biliyor?*
}

\section{What Do Preschool Children Know About Space?}

\author{
Ayşegül KÜçÜK ${ }^{* \star} \quad$ Canan LAÇiN şiMŞEK ${ }^{* \star *}$
}

Öz. Çocukluk çağı, özellikle okul öncesi dönem, insanların en meraklı, öğrenmeye en istekli oldukları dönemdir. Çocuklar, etraflarında olan her şeyi gözlemlemeye, keşfetmeye ve onlara anlam yüklemeye çalışırlar. Bu çalışmada, çocukların çok merak ettikleri konulardan biri olan uzay konusu ele alınarak, çocukların neler düşündükleri belirlenmeye çalışılmıştır. Çalışma, fenomenolojik bir çalışmadır. Sakarya ilinde yer alan bir özel anaokulun beş (4875 ay) yaş grubu ile çalışma gerçekleştirilmiştir. Çalışmaya dokuz çocuk katılmıştır. Veriler odak grup görüşmesi aracılı̆̆ıyla toplanmıştır. Görüşme soruları yarı yapılandırılmış olarak hazırlanmıştır. Yapılan görüşmeler sonucunda, çocukların uzayı çok merak ettikleri, uzayı büyük bir boşluk olarak tanımladıkları görülmüştür. Çocuklar, uzayda güneş, ay, dünya, yıldızlar, gezegenler olduğu, dünyanın yuvarlak olduğunu belirtmişlerdir. Bunun yanında, okulöncesi dönemde bulunmalarına rağmen, güneşin bir yıldız olduğunu ve gezegenlerin isimlerini bilen çocukların olduğu tespit edilmiştir. Elde edilen bulgular, aile ilgisinin kavram gelişiminde ne kadar önemli olduğunu gösterir niteliktedir.

Anahtar Kelimeler: Okul öncesi, uzay, kavram gelişimi, çocukların düşünceleri.

\begin{abstract}
Childhood, especially preschool period, is the period in which people are the most cruious and the most willing to learn something. Children try to observe, explore and make sense of all things around them. The subject of this study is one of the subjects that kids are the most curious about; the space and trying to understand what kids think about it. This is a phenomenological study. It was carried out at a private kindergarten in Sakarya, with the kids of 5 (48-66 months) years old age group. 9 kids participated to the study. The data was collected with focus group interview. The questions of interview were prepared as semi-structured. As a result of interviews, it was observed that children wonder about space so much and they define it as a huge emptiness. The children stated that there are sun, moon, earth, stars and planets in the space. Although they are just preschool kids, there are some kids who know that the earth is round, the sun is a star, names of the planets. These findings show that familys' attention is vey important at conceptual development.
\end{abstract}

Toplumsal Mesaj. Bu çalışmada, çocukların çok merak ettikleri konulardan biri olan uzay konusu ele alınarak, çocukların neler düşündükleri belirlenmeye çalışılmıştır. Elde edilen bulgular, aile ilgisinin kavram gelişiminde ne kadar önemli olduğunu niteliktedir.

Public Interest Statement. The subject of this study is one of the subjects that kids are the most curious about; the space and trying to understand what kids think about it. Findings show that familys' attention is vey important at conceptual development.

Keywords: Preschool, space, conceptual development, thoughts of the children.

\footnotetext{
* Bu çalışma VIII. Uluslararası Lisansüstü Eğitim Sempozyumunda bildiri olarak sunulmuştur.

** Sakarya Üniversitesi, Eğitim Bilimleri Enstitüsü, Fen Bilgisi Eğitimi Bölümü, aysegulkucuk90@gmail.com

*** Doç. Dr., Sakarya Üniversitesi, Eğitim Fakültesi, Matematik ve Fen Bilimleri Anabilim Dalı, csimsek@sakarya.edu.tr 


\section{GíRiş}

Evren, oldukça ilgi çekici, zengin ve şaşırtıcı olgu ve olaylarla doludur. Çocuklar, bu olgu ve olaylara karşı derin bir ilgiye sahiptirler (Okan, 1993). Çevrelerinde gördükleri her şey onlar için yeni bir durumdur. Doğayı, mevsimleri, gece gündüz olaylarını, makineleri, hayvanları, dinozorları, yıldızları, ayı, güneşi ve benzeri bir çok şeyi merak ederler. Bu merak onları keşfetmeye yöneltir. Çocuklar çevrelerini keşfettikçe, olaylar arasında benzerlikleri, farklııkları ayırt etmeye başlarlar. Gözlemledikleri her şey ile ilgili fikirler üretirler, kendilerince hipotezler kurar ve bunları test ederler. İşte bu yüzden, okul öncesi dönem, çocuklar için kritik bir dönem olup doğru yönlendirme yapılması oldukça önemlidir. Çünkü, bu dönemde çocuklar kavramlar geliştirmektedirler. Ilk başlarda, o an için amaçlarına uyan ancak geniş kapsamlı olmayan ve ayrıntı içermeyen gözlemler yaparken, bu durum yaş ilerledikçe yine artan deneyimlere bağlı olarak detaylı bir hal alır ve belirli bir probleme ilişkin gözlemlere doğru ilerler (Harlen, 1985). Bu süreç kavram gelişimini destekler. Çocuklar bu kavramları kazanırken, yeni edindikleri kavramları uygulamalarını, var olan kavramları genişletmelerini ve yeni kavramlar üretmelerini sağlayan yöntemler geliştirirler (Akman, Üstün ve Güler, 2003).

Çocukların doğuştan gelen bu merakları okul öncesi fen eğitimi ile desteklenir. Okul öncesi fen eğitimi aracılığıyla, çocukların gözlemler yapmaları ve çevrelerini tanımaları için fırsatlar yaratılır. Okul öncesi fen eğitiminde sunulan konulardan bazıları şunlardır: hava ve hava olayları, yüzme batma, doğa olayları, vücudumuz, sağlığımız, besinler, hayvanlar, bitkiler, canlı/cansız varlılar, mevsimler, ışık, ses, dünya ve uzay (Alabay, 2013). Erken çocukluk döneminde, çocukların bu kavramlarla ilgili neler düşündüklerinin, gözlemledikleri olaylarla ilgili ne tür ilişkilendirmeler yaptıklarının, gördükleri olaylara nasıl anlamlar yüklediklerinin anlaşııması kavram gelişiminin nasıl gerçekleştiğinin anlaşılması açısından oldukça önemlidir. Okul öncesinde yapılan kavram gelişimiyle ilgili çalışmalar incelendiğinde, bitkiler (Christidou ve Hatzinikita, 2006), canlılar (Backscheider, Gelman ve Shatz, 1993; Chalufour ve Worth, 2006; Zogza ve Papamichael, 2000; Bahar, Cihangir ve Gözün, 2008), ışık (Ravanis, Christidou ve Hatzinikita, 2013; Segal ve Cosgrove, 1993), çevre (Taşkın ve Şahin, 2008), elektrik (Solomonidou ve Kakana, 2000), manyetizma (Ravanis, 1994; Christidou, Kazela, Kakana ve Valakosta, 2009), yüzme batma (Elmalı ve Laçin-Şimşek, 2017); gece gündüz (Saçkes, Smith ve Trundle, 2016); bulut, yağmur ve gökkuşağı (Kikas, 2010) gibi kavramların çalışıldığı görülmüştür.

Bu çalışmada, uzay kavramı ele alınmıştır. Okul öncesi fen ve doğa köşesi etkinlikleri arasında yer alan konulardan bir tanesi olması bu konunun seçiminde etkili olmuştur. Ayrıca, güneş, ay, yıldızlar ve gezegenlerin çocukların ilgisini çeken konular arasında yer alması da önemli görülmüştür. Yapılan çalışmalarda, bu ilgiyi gösterir niteliktedir. Ceylan, Gözün-Kahraman ve Ülker (2015) tarafından yapılan bir çalışmada anneler çocuklarının en çok merak ettikleri konular arasında uzay konusunun geldiğini belirtmişlerdir. Laçin Şimşek'in (2007) yaptığı çalışmalarda da, öğrencilerin en çok öğrenmek istedikleri konular arasında, dünya, gezegenler ve uzay konusu geldiği bulunmuştur. ilgilerini çok çeken bu konu ile ilgili öğrencilerin ne tür bilgi ve düşüncelere sahip olduklarının tespit edilmesinin önemli olduğu düşünülmektedir.

\section{YÖNTEM}

Çalışmada nitel araştırma desenlerinden fenomonoloji kullanılmıştır. Fenomenolojik yaklaşımın odak noktası, öznel deneyimdir. Bu yaklaşım, bireyin kişisel dünya görüşüyle ve olayları yorumlamasıyla yani, bireyin fenomenolojisiyle ilgilenir. Fenomenolojik yaklaşımda araştırmacı, olaylara ya da fenomenlere hiçbir ön kavram ya da kuramsal düşünce empoze etmeden, birey tarafından yaşandığı gibi anlamaya çalışır. Fenomenografik araştırma öğrencilerin öğrenirken ne yaptıklarını ve öğrenme konusunda ne tür yaklaşımlar sergilediklerini anlamaya çalışır (Çekmez, Yıldız ve Bütüner, 2012). 


\section{1 Çalışma Grubu}

Çalışma grubu, kolay ulaşılabilir örneklem yoluyla oluşturulmuştur. Çalışmaya, Sakarya ili Hendek illçesinde bulunan bir özel okula devam eden anasınıfı öğrencileri katılmıştır. Çalışmada, dokuz öğrenci yer almıştır. Öğrencilerin üçü kız altısı erkektir ve yaşları 59 ay ile 75 ay arasında değişmektedir.

\subsection{Verilerin Toplama Araçları}

Araştırmanın verileri, odak grup görüşmesi yapılarak toplanmıştır. Odak grup görüşmesi ılımlı ve tehditkar olmayan bir ortamda önceden belirlenmiş bir konu hakkında algılar elde etmek amacıyla dikkatle planlanmış bir tartışma seri" olarak tanımlanabilir (Yıldııım ve Şimşek, 2016). Görüşmede, yarı yapılandııımış sorular sorulmuştur. Görüşmede sorulacak sorular, araştırmacılar tarafından hazırlanmıştır. Hazırlanan bu sorular, iki fen eğitimcisine sorularak, uzman görüşü alınmıştır. Uzmanların görüşleri doğrultusunda, yapılan düzeltmeler sonunda görüşme soruları oluşturulmuştur. Çalışmada sorulan sorular şu şekildedir:

1. Uzayı merak ediyor musunuz?

2. Uzayda neler var?

3. Uzay ile ilgili neler biliyorsunuz?

4. Uzayda yaşayan canlılar var mı? Varsa, neye benziyorlar?

5. Uzaya gitmek ister misiniz?

6. Uzay ile ilgili bilgilerinizi nereden öğrendiniz?

Görüşmeler kamera ile kayıt altına alınmıştır. Kamera kaydı için velilere izin yazısı gönderilerek, izinleri alınmıştır.

\subsection{Verilerin Analizi}

Verilerin çözümlenebilmesi için, öncelikle kamera görüntüleri transkript edilmiştir. Transkript edilen veriler, araştırmacılar tarafından birbirinden bağımsız olarak çözümlenmiştir. Ardından araştırmacılar bir araya gelerek bulguları karşılaştırmış ve son halleri verilmiştir.

Çalışmada elde edilen bulgular sunulurken, güvenirliliği arttırmak için görüşmeler, doğrudan alıntılar yapılarak sunulmuştur. Alıntılar yapııırken, çocukların isimleri değiştirilerek yeni isimler verilmiştir ve yaşları ay olarak parantez içerisinde gösterilmiştir. Örneğin, 65 aylık olan Meltem, Meltem (65) şeklinde gösterilmiştir. Konuşmalardaki duraklamalar .... simgesiyle, ek açıklamalar [..] simgesi ile gösterilmiştir. Öğrenci alıntıları italik olarak gösterilmiştir.

\section{BULGULAR}

Odak grup görüşmelerinde dokuz çocuk yer almıştır. Ancak, çocuklardan üçü sadece ilk soruya cevap vermiş diğer sorularda sessiz kalmışlardır. Araştırmacının bütün çabalarına rağmen, konuşmalara katılmamışlardır. İlk soru haricinde elde edilen bulgular 6 çocuğun katıımıyla elde edilmiştir. Çalışmanın amacı, çocukların neler bildiklerini ortaya çıkarmak olduğu için, elde edilen verilerin sıklıkları hesaplanmamış, genel olarak ne bildikleri ortaya konmuştur. Yarı yapılandırılmış sorular aracılığılla elde edilen bulgular aşağıda sunulmuştur.

1.“ Uzayı merak ediyor musunuz?" sorusuna verilen cevaplar

Bir çocuk hariç hepsi hep birlikte evet diye cevap vermişlerdir. Meltem(65) ise "Ben hiç merak etmiyorum çünkü... çünkü ben biliyorum uzayı" demiştir.

2. “ Uzayda neler var?” sorusuna verilen cevaplar

Çocuklar uzayda neler olduğuyla ilgili şu ifadelerde bulunmuşlardır: Dünya, Güneş, Merkür, Mars, Jüpiter, Gezegenler, Yıldızlar, Karadelik ve Ay.

3. “ Uzayla ilgili neler biliyorsunuz?" sorusuna verilen cevaplar

Araştırmacı: Uzayla ilgili neler biliyorsunuz? 
Erdem(74) : Ben çok şeyi merak ediyorum, Dünya'nın yuvarlak olduğunu biliyorum.

Meltem(65) : Güneş, Merkür, Dünya, Mars

Yavuz(75): Karadelik

Araştırmacı: Peki neler bu saydıkların Güneş, Merkür, Dünya, Mars ne?

Meltem(65) : Bunlar gezegenler. Tam sekiz tane gezegen var. En tehlikeli gezegenimiz mavi delik ve jüpiterin deliği çok tehlikeli. içinde büyük fırtınalar oluşuyor.

Ayşe(73): Bizim Dünya'mız mavi ve yeşilden oluşur.

Araştırmacı: Siz bunları nereden biliyorsunuz?

Meltem(65) : Benim bir kitabım var uzayla ilgili oradan biliyorum.

Erdem(74) : Bir şey diyeceğim uzayda mini minnacık bir gezegen var, o gezegen ne?

Meltem(65) : Plüton var o da cüce gezegen.

Yavuz(75) : Ben kara deliği merak ediyorum.

Araştırmacl: Kara delik nedir sence?

Yavuz(75) : Insanları içine çekiyor.

Meltem(65) : Mavi deliğin içinde fırtına var, rüzgar var

Araştırmacı: Peki uzay nasıl bir yer?

Ayşe(73): Gezegenler var, ay var.

Erdem(74) : Yıldızlar var, ay var. Güneş de bir yıldız.

Meltem(65) : Jüpiter var. O tehlikeli bir gezegen. Bazıları tehlikeli bazıları tehlikeli değil. Çünkü bazıları güneşe yakın olduğu için çok sıcaktır.

Zehra(59): Yıldızlar da var

Yukarıda verilen diyalogda da görüldüğg̈ üzere, çocukların içinde, dünyanın yuvarlak olduğunu, sekiz gezegen olduğu, Plüton'un cüce gezegen olduğunu (Araştırmacı notu: bir dönem plüton, gezegen sınıflandırmasından çıkarılarak cüce gezegen olarak tanımlanmıştır), Güneşe yakın gezegenlerin sıcak olduğu, Jüpiter'in tehlikeli bir gezegen olduğunu [çok fırtına olmasından kaynaklı çocuk bu şekilde tanımlıyor, arş. notu], karadeliği, dünyanın yeşil ve mavi ağırlıklı bir görünüşe sahip olduğunu bilen çocuklar vardır. Ayrıca, güneşin bir yıldız olduğunu, astronotların uzaya araştırma yapmak için gittiklerini, onların özel kıyafetlerinin olduğunu ve uzaya roketle gittiklerini de bilmektedirler.

4. " Sizce uzaylılar var mıdır?" sorusuna verilen cevaplar

Araştırmacı: Peki uzayda yaşayan canlılar var mı?

Çocuklar: Var.

Yavuz(75) : Adamlar var.

Araştırmacı: Nasıllar? Bize benziyorlar mı?

Ayşe(73): hayır, onlar uzaylılar

Araştırmacı: Nasıl uzaylılar bana tarif eder misin?

Mert: Uzaylı diye bir şey yok.

Meltem(65) : Onlar gerçek değil

Araştırmacı: İzin verin tarif etsin arkadaşınız.

Meltem(65) : Uzaylı diye bir şey yok aslında.... Orda ne canlıları var söyleyeyim mi... astronotlar var orda, uzayı keşfetmeye gitmişler.

Ayşe(73): Orda çok çok durduğunda nefessiz kalabilirsin

Araştırmacl: Neden?

Ayşe(73): Bence canlı yok çünkü orda nefes alamıyorsun. 
Meltem(65) : Eğer uzay kaskını takmazsan nefes alamıyorsun ama uzay kaskını takarsan nefes alabiliyorsun.... Astronot kıyafetinde böyle bir şapka var, onu takıyorlar camı da böyle[eliyle tarif ediyor], nefes alabiliyorlar.

Araştırmacı: [Ayşe(73)'ye dönerek] sen uzaylıların nasıl olduğunu bana tarif edebilecek misin?

Erdem(74) : Uzaylı diye bir şey yoktur

Araştırmacl: İin ver arkadaşın anlatsın

Ayşe(73): Bize benzemiyor falan, onların yüzü bizimki gibi değil, onların ayakları falan çok değişik

Araştırmacı: Nasıl mesela?

Yavuz(75) : Sivri sivri

Meltem(65) : Sivri sivri değil onların rengi yemyeşil.

Ayşe(73): Yemyeşil, bizden çok değişikler.

Meltem(65) : Tek gözlü uzaylı da var. Ondan adamlar çok korkuyor.

Uzaylıların olup olmadığı ile ilgili olarak, Erdem(74) uzaylıların olmadığını söyleyip, ısrarla konuşmaları bastırmaya çalışsa da, diğer çocuklar uzaylıların olduğunu belirtmişlerdir. Uzaylıların neye benzedikleri sorusu üzerine, uzaylıları yeşil renkli, sivri şekilli, farklı ayaklı tek gözlü şeklinde tarif etmişlerdir.

5.“Uzaya gitmek ister miydiniz?" sorusuna verilen cevaplar

Bu soru karşısında bazı çocuklar gitmek istediklerini belirtirken, bazıları gitmek istemediklerini söylemişlerdir. Buna gerekçe olarak da, "uzayda nefes alınamadığııı" belirtmişlerdir. Diğer yandan, gitmek isteyen çocuklar, "astronotların özel kıyafetlerinin olduğunu bu yüzden nefes alınabileceğini" söylemişlerdir.

6.“ Uzayla ilgili bilgileri nereden öğrendiniz?" sorusuna verilen cevaplar

Görüşmeye katılan çocukların verdikleri cevaplar karşısında, bu bilgileri nereden öğrendikleri sorulmuştur. Meltem(65), "Benim bir kitabım var uzayla ilgili oradan biliyorum, annem okuyor." derken, Erdem (74) ise, "annem ile konuşuyoruz, annemden öğrendim" şeklinde cevap vermiştir.

\section{TARTIŞMA VE SONUÇ}

Okul öncesi dönemde bulunan çocukların uzay ile ilgili bildiklerini ortaya çıkarmak amacıyla yapılan bu çalışmada, çocukların uzayda güneş, ay, gezegenler, yıldızlar olduğunu, uzaya astronotların gittiğini bildikleri, uzaylıların olup olmadığıyla ilgili kafalarının karışık olduğu görülmüştür. Bunun yanında, çalışmada oldukça şaşırtıcı sonuçlar elde edilmiştir. Çocuklar arasında, okul öncesi dönemde bulunmalarına rağmen, dünyanın yuvarlak olduğunu, güneşin bir yıldız olduğunu, gezegenlerin hepsinin ismini, hatta güneşe yakınlıklarına göre sıcaklıklarını, bazı gezegenlerde çok fırtına olduğunu, Plüton'un cüce gezegen olduğunu, uzaya astronotların gittiğini, astronotların özel kıyafetlerinin olduğunu, uzaya roketle gidildiğini bilen çocuklar bulunduğu tespit edilmiştir. Bu bulgular arasında Güneş'in bir yıldız olduğunu bilmeleri dikkat çekicidir; çünkü yapılan bazı çalışmalarda, 6. sınıf öğrencilerinin (Ekiz ve Akbaş, 2005) hatta üniversite öğrencilerinin (Emrahoğlu ve Öztürk, 2009) bile güneşin bir yıldız oluğunu bilmedikleri bulunmuştur.

Çocukların bir kısmı, bütün gezegenlerin isimlerini bilmektedir, hatta bir öğrenci güneşe uzaklıklarına göre sıralayabilmektedir. Gezegenlerin bir kısmında olan doğa olaylarından haberdar olan çocuk da bulunmaktadır.

Elde dilen bazı bulgular, yaş grubu açısından bakıldı̆̆ında beklenenin üstündedir. Kolay ulaşılabilir örnekleme yoluyla seçilen çalışma grubundan elde edilen verilerde iki çocuğun cevapları öne çıkmaktadır. Bu verileri elbette ki genellemek mümkün değildir. Ancak, çocuklara bu bilgileri nereden öğrendikleri sorulduğunda, cevaplarıyla öne çıkan iki çocuğun da annesinden öğrendiğini belirtmesi dikkate değer bir bulgudur. Aile ile konuşabilen, merak ettiği sorulara cevaplar alabilen, kitaplar 
okunan çocukların kavram gelişimi farklı olarak ilerlemektedir (Laçin- Şimşek ve Tezcan, 2008). Ailenin ilgisi kavram gelişimini olumlu şekilde etkilemektedir. Çetin, Yavuz, Tokgöz ve Güven (2012) yaptıkları çalışmada da, çocukların uzay ile ilgili bildiklerini ailelerinden, kitaplardan ve çizgi filmlerden öğrendiklerini ifade etmişlerdir. Çocuğun ilk eğitimcileri aslında anne ve babalardır (Kuru, 2015), çocuklar, ilk bilimsel deneyimlerini anne ve babalarından öğrenmektedirler dolayısıyla anne babaların duyarlı davranarak çocukların sordukları sorulara açıklayıcı cevap vermeleri (Ceylan, Gözün-Kahraman ve Ülker, 2015) kavram gelişimi açısından oldukça önemlidir. Çocuklara uzaylı var mıdır diye sorulduğunda, iki gruba ayrılarak bir kısmı var bir kısmı yok demesine rağmen, neye benziyorlar sorusu üzerine, bir çocuk hariç hep birlikte tarif etmeye başlamışlardır. Çocukların yaptıkları tariflerde, çizgi film ve televizyonlarda gördükleri imgeler üzerinden anlatmaya çalıştıkları görülmektedir. Bu durum da, kavram gelişiminde, medyanın etkisine bir örnek olarak değerlendirilebilir.

Çalışmada elde edilen bulgular sonucunda, çocukların ilgi duydukları alanlar ile ilgili onlara yardımcı olunduğunda, sorularına cevap verildiğinde, birlikte ilgili kitapları okuduklarında, kavramların daha çabuk ve düzgün geliştiği görülmektedir. Bu da, kavram gelişiminde ailenin ne kadar önemli olduğunu göstermektedir.

\section{5. ÖNERILER}

Bu çalışmada, uzay konusu ele alınmıştır. Çocukların günlük hayatlarında gözlemledikleri ve ilgilerini çeken diğer fen konularında da benzer çalışmalar yapılabilir. Çalışmada, odak grup görüşmesi yapılmıştır. Gözlemler, çizimler, bireysel görüşmeler yapılarak veri kaynakları çeşitlendirilebilir. Çalışmaya, veli boyutu da katılarak, onların çocuklarının fen konularına yönelik ilgilerini nasıl yönlendirdikleri araştırılabilir.

\section{Kaynakça}

Akman, B., Üstün, E. ve Güler, T. (2003). 6 Yaş Çocuklarının Bilim Süreçlerini Kullanma Yetenekleri. Hacettepe Üniversitesi Ĕgitim Fakültesi Dergisi, 24, 11-14.

Alabay, E. (2013). Okul Öncesi Fen Eğitiminde Fen Programları. Akman, B., Uyanık Balat, G., Güler, T. (ed). Okul Öncesi Dönemde Fen eğitimi. Ankara: Pegem Akademi.

Backscheider, A. G., Gelman, S. A. ve Shatz, M. (1993). Preschoolers' Ability to Distinguish Living Kinds as a Function of Regrowth. Society for Research in Child Development, 64(4), 1242-1257.

Bahar, M., Cihangir, S. ve Gözün, Ö. (2008). Okul Öncesi ve Illköğretim Çağındaki Öğrencilerin Canlı ve Cansız Nesneler ille illgili Alternatif Düşünce Kalıpları. infobank.fedu.metu.tr/ufbmek5/bkitabı/PDF/Fen/Bildiri/t65d.pdf adresinden 19.05.2016 tarihinde alınmıştır.

Ceylan, Ş., Gözün-Kahraman, K. ve Ülker, P. (2015). Çocukların Meraklarına illişkin Annelerin ve Öğretmenlerin Düşünceleri: Bilim Kavramı. Sosyal Bilimler Enstitüsü Dergisi. 5(1), 1-16.

Chalufour, I. ve Worth, K. (2006). K Today: Teaching and Learning in The Kindergarten Year. Science in Kindergarten. 85-94

Christidou, V. ve Hatzinikita, V. (2006). Preschool Children's Explanations of Plant Growth and Rain Formation: A Comparative Analysis. Research in Science Education. 36(3), 187-210

Christidou, V., Kazela, K., Kakana, D. ve Valakosta, M. (2009). Teaching Magnetic Attraction to Preschool Children: A comparison of different approaches. International Journal of Learning. 16, 115-128.

Çekmez, E., Yıldız, C. ve Bütüner, S. Ö. ve (2012). Fenomengrafik Araştırma Yöntemi. NEF-EFMED. 6(2), 77-102.

Çetin, T., Yavuz, T.., Tokgöz, B. ve Güven, G (2012). Okul Öncesi Dönemdeki Çocuklara (62-72 ay) Uzay Kavramı Öğretimi. GEFAD/GUJGEF 32(3), 715-731. 
Ekiz, D. ve Akbaş, Y. (2005). İlköğretim 6. sınıf öğrencilerinin astronomi ile ilgili kavramları anlama düzeyi ve kavram yanılgıları. Milli Eğitim Dergisi, 165.

Elmalı, Ş. ve Laçin-Şimşek, C. (2016). Okul Öncesi Çocukların Yüzme ve Batma Kavramı ile illgili Düşünceleri. 12. Ulusal Fen Bilimleri ve Matematik Eğitimi Kongresi, Trabzon, Eylül, 2016.

Emrahoğlu, N. ve Öztürk, A. (2009). Fen Bilgisi Öğretmen Adaylarının Astronomi Kavramlarını Anlama Seviyelerinin ve Kavram Yanılgılarının İncelenmesi Üzerine Boylamsal Bir Araştırma. Ç.Ü. Sosyal Bilimler Enstitüsü Dergisi. 18(1), 165-180.

Harlen, W. (1985). Teaching and learning primary science. London, Harper.

Kikas, E. (2010). Children's Thinking: Clouds, rain, and rainbow in children's explanations. Mäetagused, 46, 139-156.

Laçin Şimşek, C. (2007). Öğrenciler Fen ve Teknoloji Dersinde Ne Öğrenmek i̇stiyorlar? VI. Ulusal Sınıf Öğretmenliği Eğitimi Kongresi, Bildiriler Kitabı, 39-42, Anadolu Üniversitesi, Eskişehir.

Laçin Şimşek, C. ve Tezcan, R. (2008). Çocukların Fen Kavramıyla Illgili Düşüncelerinin Gelişimini Etkileyen Faktörler. ilköğretim Online, 7(3), 569-577.

Okan, K. (1993). Fen Bilgisi Öğrtimi. Ankara: Okan yayınları.

Ravanis, K. (1994). The Discovery of Elemantary Magnetic Properties in Preschool Age. European Early Childhood Education Research Journal. 2(2), 79-91.

Ravanis, K., Christidou, V. ve Hatzinikita, C. (2013). Enhancing Conceptual Change in Preschool Children's Perpresentations of Light: A Sociocognitive Approach. Reseach in Science Education. 43(6), 2257-2276.

Segal, M. ve Cosgrove, M. ve (1993). The Sun Is Sleeping Now: Early Learning About Light And Shadows. Reseach in Science Education. 23(1), 276-285.

Solomonidou, C. ve Kakana, D. M. (2000). Preschool Children's Conceptions About the Electric Current and the Functioning of Electric Appliances. European Early Childhood Education Research Journal, 8(1), 95 111.DOI:10.1080/13502930085208511.

Saçkes, M., Smith, M. M. ve Trundle, K. C. (2016). US and Turkish Preschoolers Observational Knowledge of Astronomy, International journal of Science Education. 38(1), 116-129.

Taşkın, Ö. ve Şahin, B. (2008). Çevre Kavramı ve Altı Yaş Okul Öncesi Çocuklar. Pamukkale Üniversitesi Eğitim Fakültesi Dergisi, 23(23), 1-12.

Yıldırım, A. ve Şimşek, H. (2016). Sosyal Bilimlerde Nitel Araştırma Yöntemleri. (10. Baskı). Seçkin Yayınevi.

Zogza, V. ve Papamicheal, Y. (2000). The Development of the Concept of Alive By Preschoolers Through A Cognivive Conflict Teaching Intervention. European Journal of Psychology of Education. 15(2), 191-205 


\section{Extended Summary}

on the increased experience with age (Harlen, 1985). This process fosters concept development. As children acquire these concepts, they develop methods that enable them to apply new concepts, expand existing concepts, and produce new concepts (Akman, Üstün \& Güler, 2003).

This innate curiosity of children is promoted by preschool science education. Opportunities are created through preschool science education for children to make observations and get to know their environment. Some topics included in preschool science education are as follows: weather and weather events, floating and sinking, natural events, body, health, food, animals, plants, living and non-living things, seasons, light, sound, the Earth, and space (Alabay, 2013).

This study addresses the concept of space. The choice of this topic is because of the fact that space is one of the topics included in the preschool science and nature corner activities. It is also worthy of consideration that the sun, moon, stars, and planets are included in children's areas of interest. Thus, it is of great significance to be informed of children's knowledge and ideas about this subject which attracts their interest a lot.

\section{Methodology}

This is a phenomenological study.

\section{Study Group}

The study group was formed using convenience sampling. The study was conducted with 9 preschool students attending a private school in Hendek district of Sakarya province.

\section{Data Collection Tools}

The research data were collected through focus group interviews. Semi-structured questions prepared by the researchers were asked in these interviews. These questions were presented to two science educators to obtain expert opinions. In line with the expert opinions, the interview questions were finalized through the amendments made. The questions are as follows:

1. Are you curious about space?

2. What is there in space?

3. What do you know about space?

4. Are there aliens? And what do they look like?

5. Would you like to go to space?

6. Where did you learn the answers you gave?

The interviews were recorded by a camera. The parents of the responding children were sent a permission slip to obtain their consent for camera recording.

\section{Data Analysis}

In order to analyze the data, the camera records were first transcribed. The transcribed data were analyzed independently by the researchers. Then the researchers came together to compare and finalize their results. This study presents the results through direct quotations of the interviews to increase reliability.

\section{Results}

This study aiming to reveal preschool children' knowledge about space has found the following: children know that there is the sun, moon, planets, and stars in space; astronauts go to space; but they are confused about the existence of aliens. The study has also yielded quite surprising results. Although they are only at the preschool age, some of the responding children know the planet Earth is round; the sun is a star; the names of all the planets; and even their temperatures according to their distance to the sun; some planets are very stormy; Pluto is a dwarf planet; astronauts go to space; astronauts wear special suits; and they go to space by a space rocket. Among these results, it 
is quite remarkable that they know the sun is a star, considering that previous research reports that $6^{\text {th }}$-grade (Ekiz \& Akbaş, 2005) students and even university students (Emrahoğlu \& Öztürk, 2009) do not know the sun is a star. Some of the children know the names of all the planets, and a student can even sort them by their distance to the sun. There are children who are aware of natural events that occur in some planets.

\section{Discussion and Conclusion}

These results are far beyond expectations considering the age group. The answers of two children are distinguishable in the data obtained from the study group selected through convenience sampling. It is of course not possible to generalize the data. However, it is worthy of attention that when the children standing out with their answers were asked how they learned this information, they responded that they learned from their mothers. Children who read books and can talk to the family and get answers to their curious questions have a distinct process of concept development (Laçin-Şimşek \& Tezcan, 2008). Family care has a positive effect on children's concept development. Çetin, Yavuz, Tokgöz and Güven (2012) report that children learn about space from their families, books, and cartoons. The first educators of a child are actually parents (Kuru, 2015). Children learn their first scientific experience from their parents. Thus, it is of key importance for concept development that parents sensitively respond to questions their children ask (Ceylan, Kahraman \& Ülker, 2015).

When children were asked whether there are aliens, they split into two groups, one approving the existence of aliens and the other rejecting it. Except one child, they all described what an alien looks like. In their descriptions of aliens, children used images they saw in cartoons and on television. This situation can be regarded as an example of the influence of the media on concept development. This shows how important the family is in concept development.

\section{Suggestions}

The study addressed space. Further research can be conducted on other science topics that children observe and see in their daily lives.

This study used focus group interviews. Data sources can be diversified through observations, drawings, and individual interviews.

Further research can also include parents to investigate how they direct their children's attention to science. 